\title{
Recombinant Inhibin B
}

National Cancer Institute

\section{Source}

National Cancer Institute. Recombinant Inhibin B. NCI Thesaurus. Code C1349.

A recombinant therapeutic agent which is chemically identical to or similar to an endogenous glycoprotein which inhibits pituitary production of follicle-stimulating hormone (FSH). Produced and secreted by the testis or ovarian follicle, endogenous inhibin B contributes to the control of gametogenesis, embryonic and fetal development, and hematopoiesis. ( $\mathrm{NCl04)}$ 